\title{
IDENTIFICATION OF OPTIMIZATION AREAS OF A TRANSTIBIAL PROSTHESIS THROUGH THE POTENTIALS OF ADDITIVE MANUFACTURING PROCESSES
}

\author{
Steffan, Kay-Eric; \\ Fett, Michel; \\ Kurth, Daniel; \\ Kirchner, Eckhard \\ Technische Universität Darmstadt
}

\begin{abstract}
Additive manufacturing enables new possibilities for the design of end products. These are rooted in the potentials of the manufacturing technology, such as flexible, tool-free production. These potentials can be used for the economic and flexible production of customized products. To support the use of the potentials, a development method was created which identifies optimization areas within a product. Therefore, the complexity is reduced by using of product functions. Characteristic functions and structural configurations are used to identify optimization areas. This contribution describes the application of the new development method to an existing mechanical transtibial prosthesis. In doing so optimization areas are identified which may make use of the potentials provided by additive manufacturing. One area is the interface between the prosthesis and the ground. By analyzing walking environments and the gait cycle the need for walking assistance on deformable surfaces was identified. Significant improvements were achieved through a functional integrated, additive manufactured foot sleeve.
\end{abstract}

Keywords: Design for Additive Manufacturing (DfAM), Product modelling / models, Additive Manufacturing, transtibial prosthesis, Biomedical design

\section{Contact:}

Steffan, Kay-Eric Werner Heinz

Technische Universität Darmstadt

Produktentwicklung und Maschinenelemente pmd

Germany

steffan@pmd.tu-darmstadt.de 


\section{INTRODUCTION}

Approximately $15 \%$ of the population suffers from a disability. About $2-3 \%$ of all people have a significant limitation in the functional range of their body due to their disability. Because of demographic changes depicted in Figure 1 (left) this percentage continues to rise (World Health Organization, 2011). When considering people with limitations, the loss of limbs, such as legs, play a significant role. In Germany, about 69 leg amputations per 100,000 inhabitants are conducted annually (Kröger et al., 2017). In the USA, this number is around 56 (Kozak and Owings, 1998) and in Sweden it is about 35 (Kamrad et al., 2020).

Affected patients can be enabled to participate in everyday life with suitable technology based medical products such as prostheses. This high number of leg amputations leads to a high demand for functional and high-quality leg prostheses. These are constructed of numerous components, of which many interact with each other. This makes them complex products. One approach to refining such complex products is by improving the involved manufacturing processes. But identifying areas which lend them self to such refinements is not always trivial. To deal with this problem, an extended approach was presented at DESIGN 2020. The approach identifies functions of products which are relevant for optimization through the potentials of the additive manufacturing (AM) (Steffan et al., 2020a). In this contribution, a mechanical transtibial prosthesis as depicted in Figure 1 (right) is investigated for optimization potentials using additive manufacturing processes. Therefore, the aforementioned approach is used.
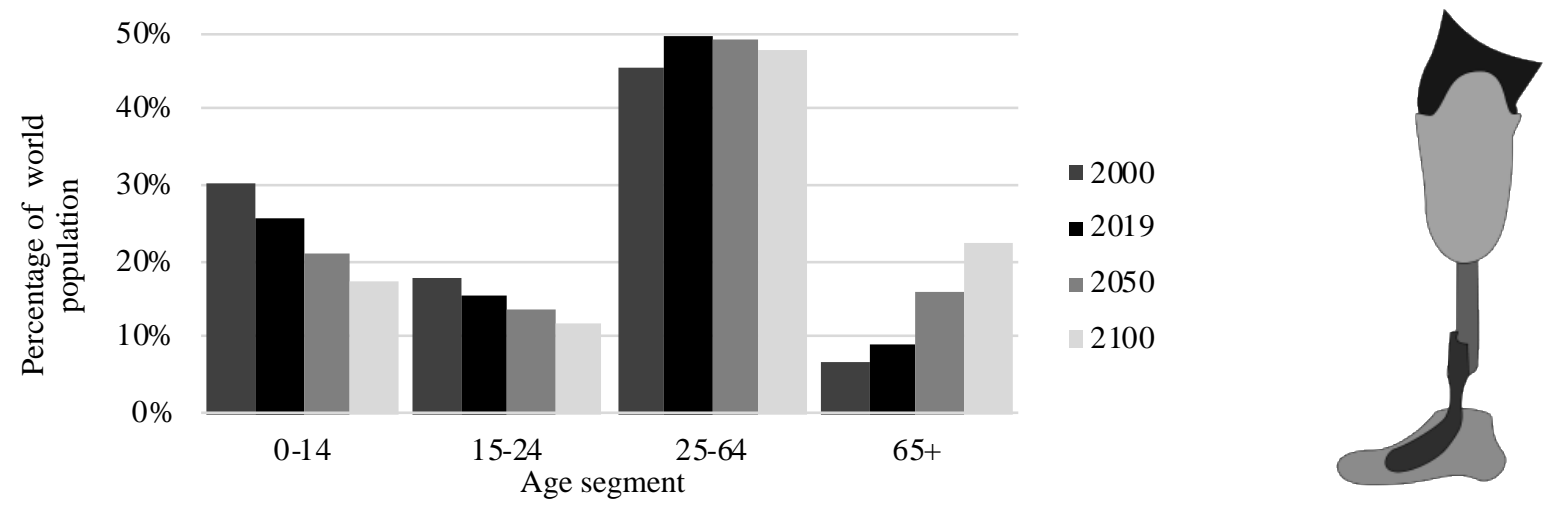

Figure 1. Graphical representation of UN estimates for the world population by broad age groups (United Nations, 2019) (left), simplified representation of a transtibial prosthesis (right)

\section{FUDAMENTALS}

This paper presents the optimization of transtibial prostheses. In the first subchapter, the general structure of prosthetic legs is presented. Additionally, technical aspects of prosthesis development are highlighted. Then current prosthesis implementations are discussed and design goals are derived. In the second subchapter, the steps of the so called extended approach are presented. Later these are used as a starting point for the optimization of the aforementioned transtibial prosthesis.

\subsection{Prosthetic assembly}

For the purposes of this contribution a prosthesis is the replacement of a missing body part. Such a prosthesis artificially reproduces the body's own functions. Furthermore, the focus of this work is on transtibial leg prostheses. These vary in size depending on their user and are available as mechatronic and mechanical versions. Mechatronic leg prostheses detect the movement of the prosthesis itself and support the walking process with actuators. In comparison, mechanical leg prostheses merely transfer the weight of the user to the ground and support the walking process through their elasticity. Nevertheless, the design of different prosthesis types is very similar and solved by means of modular systems. An individually manufactured socket encloses the user's remaining limb. The resulting firm fit of the prosthesis on the body part creates an airtight seal. This seal is used to attach the body part to the socket using a partial vacuum. The type of leg prosthesis determines the offered functionalities. For thigh prostheses, the socket is connected to a knee joint. This joint is then connected to a shaft. Placed on the end of the shaft is the prosthesis foot. For transtibial prostheses the prosthesis foot is 
directly attached to this shaft and the knee joint is omitted. The interchangeability of the modules which are used to design the prosthesis, allows for a high degree of customizability. Currently, realistic foot like silicone covers are used to make the prosthesis less conspicuous. Present developments focus on areas of customization and lightweight design (Ottobock, 2020; Össur, 2020). The aim of these developments is to improve functionality and to reduce the complexity of the prosthesis design by using existing solutions (Piazza et al., 2019). Another aspect is the basic user demand of an overall anthropomorphic appearance of the prosthesis (Kate et al., 2017). An additional area which can be optimized in order to enhance the user experience is the interface of the prosthesis to the environment. For example, one can strategically influence the walking experience for different terrains. All these optimization paths are partly contradictory to each other and can be resolved by employing additive manufacturing processes. In order to control the resulting design complexity, the number of used parts has to be limited. This can be achieved with the help of AM by creating functionally integrated components.

Considering the previously mentioned contradicting goals and the capabilities of AM, a so called extended approach was developed by Steffan et al. The approach reduces the design complexity systematically by searching for optimization areas. These are determined by analysing the individual functions of a product (Steffan et al., 2020a). How this is done will be explained in the next subchapter.

\subsection{Description of the extended approach to optimize modular products through the potentials of additive manufacturing}

Additive manufacturing offers new potentials, which include the easy adaptability of components through a tool-free production process. AM is already being used to manufacture products which are individualized to their users. Such products include hearings aids (Sonova, 2020) and fashionable prosthesis covers (Ce:koon Prothesis Covers, 2020). The layer-by-layer build process of the workpiece makes it possible to manufacture complex structures. These allow for greater design freedom and they promote function-integration and integral design. This differs from manufacturing processes such as turning and milling. The consideration of additive manufacturing during the development and design of a product requires a profound rethinking within development teams (Petrovic et al., 2011). The multitude of new potentials represents a barrier, as each potential offers different solutions.

Appropriate development methods and corresponding expertise are essential to open up new applications for additive manufacturing processes. The comprehensive use of manufacturing processes requires either experience in the field of the process or the combined use of development methods and specific expertise. One such development method was presented at DESIGN 2020. The authors process model supports the identification of components in modular products that are suitable for optimization by means of additive manufacturing The approach is based on the procedure of the VDI2221 guideline (Verein deutscher Ingenieure, 2019). This guideline is comprised of several steps describing the product development process. Thereby the product evolves from an abstract representation to more and more concrete representation. When the level of abstraction is high, it is easier to recognize interrelationships and areas for possible optimizations. Therefore, the extended approach increases the level of abstraction in order to identify optimization areas. This is done by creating a function structure of the product via a function analysis or function synthesis. This function structure can then be optimized by a function variation if necessary (Pahl et al., 2007). In a second step, the function structure of the product is used to isolate relevant optimizations areas. This done by searching for different structural configurations and the following two characteristic functions:

- Variant specific optimization: These optimization areas are along function paths which only occur in certain variants of a product and do not belong to the basic functions of all variants. In principle, these are suitable for additive manufacturing through the potential of function integration. An example is an integrated head-up display within a $3 \mathrm{D}$ printed motorcycle helmet as an optional feature (Steffan et al., 2020a).

- Individual optimization: These optimization areas can be identified on the basis of the input variables or the output variables of a function. Variables that leave the system boundary are of particular interest. If the function has different input and/or output variables for every customer the function is identified as suitable for the usage of additive manufacturing. An example for such an optimization area is the internal shape of a motorcycle helmet. This can be individualized to 
every user. Consequently one can achieve a more uniform transferal of forces from the helmet to the users head (Steffan et al., 2020a).

The identified functions are then used as variant drivers as described by Pahl and Beitz (Feldhusen et al., 2013). In the next step partial implementation solutions are determined for the previously identified functions. A systematic variation of working principles supports finding partial solutions (Pahl et al., 2007; Ponn and Lindemann, 2008; Feldhusen and Grote, 2013). Within the systematic variation AM is taken into account. This can include the feasibility of local properties (e.g. material or density) or free-form shapes. The resulting partial solutions are added to a morphological analysis. The morphological matrix is supplemented with the remaining ordinary functions and partial solutions of the product which were not specifically considered for the use with AM. Through the application of AM new synergies become possible and these become apparent with this enlarged morphological matrix. Special attention is paid to the function integration of several functions within one function carrier. This function integration can be realized, for example through an integrational design within the additively manufactured modules or via the integration of non-AM components (e.g. actuators or sensors).

After the combination of the partial solutions into principle solution variants, these are filtered through selection and evaluation methods, like the commonly employed pair-wise comparison or a point rating (Haberfellner et al., 2019). More details on the individual steps of the extended approach can be taken from (Steffan et al., 2020a). In the following chapter the extended approach is applied to an existing mechanical transtibial prosthesis.

\section{APPLICATION OF THE EXTENDED APPROACH TO A MECHANICAL TRANSTIBIAL PROSTHESIS}

In this chapter the introduced extended approach for identifying suitable functions which can be optimized by AM is applied to a transtibial prosthesis. This is done by first analysing how relevant forces are conducted through a simplified version of such a prosthesis. The analysis is then used to determine a function structure. On the basis of this function structure, promising optimization areas are derived with the help of the so-called functional characteristics. These are then examined in more detail. In the next step walking phases are analysed and design requirements are determined. These are later used for the optimization of the promising areas.

\subsection{Function structure of a mechanical transtibial prosthesis}

The function structure is synthesized by analysing which forces are transferred into the system (transtibial prosthesis) and how these are then transferred out of the system towards the walking surface. This approach for synthesizing the function structure is based on the methods described by Pahl and Beitz (Pahl et al., 2007).

The primary goal of the function structure in the context of the extended approach is the determination of relevant optimization areas.. Because of this the level of detail used within the function structure can be limited. Thus several simplifications are made. In line with this is that the transtibial prosthesis is assumed to be a single stiff body. For the sake of completeness, the elastic element which is normally present in a mechanical transtibial prostheses is later added to the function structure. To further simplify the syntheses, the forces which are transferred into the system via the leg socket are assumed to be in line with the coordinate system. This eliminates possible torques around the z-axis. The coordinate system which is used for the description is placed near the ankle of the prosthetic foot. This is done because it represents a natural joint around which the foot and the leg rotate during the different walking phases. The examined forces, torques and the coordinate system are depicted in Figure 2. 

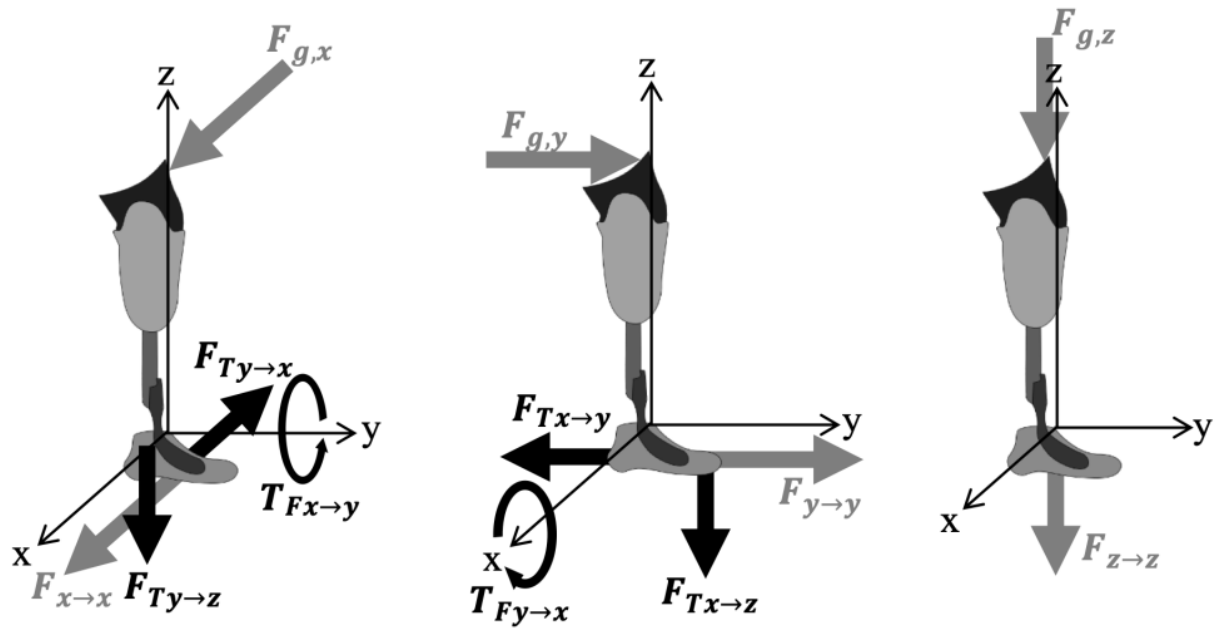

Figure 2 Schematic model of the forces affecting the prosthesis, divided into $x$-part (left), $y$-part (middle) and z-part (right). The arrow in the forces and torques indicates the input force direction and resulting direction.

The resulting simplified function structure is depicted in Figure 3. Analysing the structure reveals that forces which are transferred via the leg socket into the prosthesis follow different paths. Some forces are directly transferred to the walking surface while others are converted into torques and back into forces. This is due to the prosthesis geometry. Furthermore, the elastic elements in the prosthesis stores more or less energy during the different walking phases.

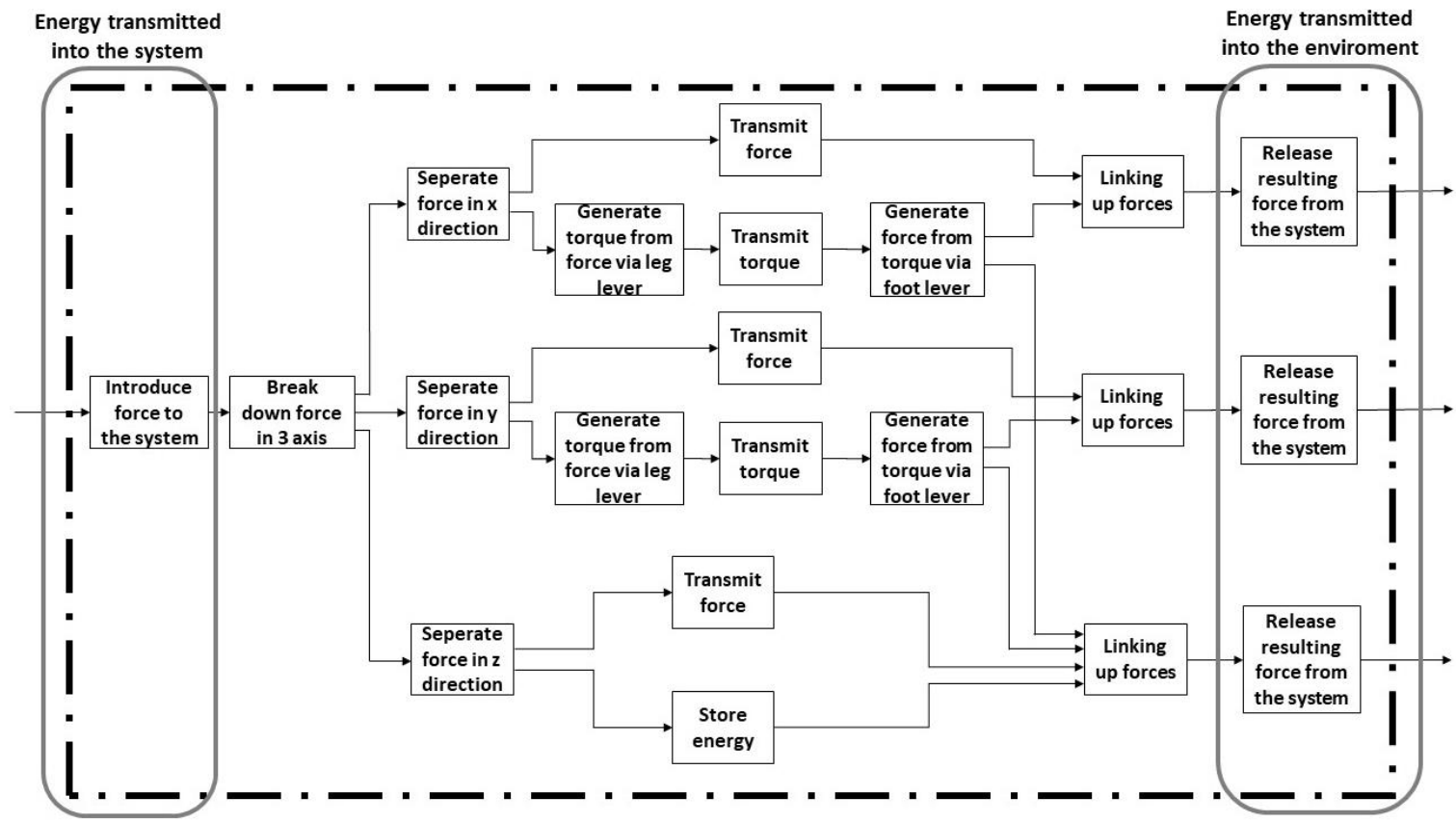

Figure 3 Function structure of a transtibial prosthesis based on the flow of mechanical energy. Functions identified by means of the second functional characteristic are highlighted in grey boxes.

\subsection{Identification of functional areas for optimization through additive manufacturing}

The function structure in Figure 3 is used during the application of the extended approach to identify optimization areas for additive manufacturing. Using the above mentioned second functional characteristic as a search criterium for such areas, leads to the highlighted functions in Figure 3 . These functions either transfer energy into the system or transfer energy from the system into the environment. Looking at the function which transfers energy into the system, one can observe that the energy is introduced as a force through the leg sockets free-form surface. This shape represents the individual geometry of the user's remaining limb. The optimization of the sockets shape 
in combination with function integration by means of additive manufacturing is already being researched (Maier, 2018).

The analysis of the functions which transfer energy from the system into the environment leads to the following key observation. The prosthetic foot is responsible for the transferal of forces to the environment. These forces are transferred via the geometry of the prosthetic foot. The mating surface of the prosthetic foot is the walking surface. It will deform according the transferred forces. The deformation of the walking surface leads to the displacement of the foot. By how much the foot is displaced is dependent on how much the walking surface deforms. This is of relevance because the walking process is negatively affected when significant foot displacement due to the deformation of the walking surface occurs. This effect is further amplified, for the case of a prosthetic foot if the walking process is supported only by a single prosthesis. This may lead to an asymmetric displacement between the prosthesis and the human foot occurs. Due to this it is of interest, to minimize the deformation of the walking surface for use case of prosthetic foot.

Hence, a solution for prosthetic feet will be developed that limits how much the walking surface deforms. As a consequence, the foot sinkage and the related negative effects on the walking process will be minimized. Two sources are used to obtain relevant information for the development process. One is the gait cycle, and the other is Schuys research on ground reaction forces (GRF) during critical phases of gait (Schuy, 2016). Relevant information from both sources will now be explained in the next subchapter.

\subsection{Gait cycle and ground reaction forces}

The central use of a prosthesis is walking. Walking itself is a well-studied research topic and thus different models exist to describe the walking process. Whittle divides the cyclical walking process into seven events. These describe the movement sequences of both legs (Whittle, 2006).

Figure 4 is used to depict these seven events. For the respective legs, they are categorized into a standing and a swinging phase. For the purposes of the following description the right leg (black) is referred to as the main leg and the left leg (grey) is called the opposite leg. Relevant information for the development process is obtained by analyzing the initial contact event and the toe off event.

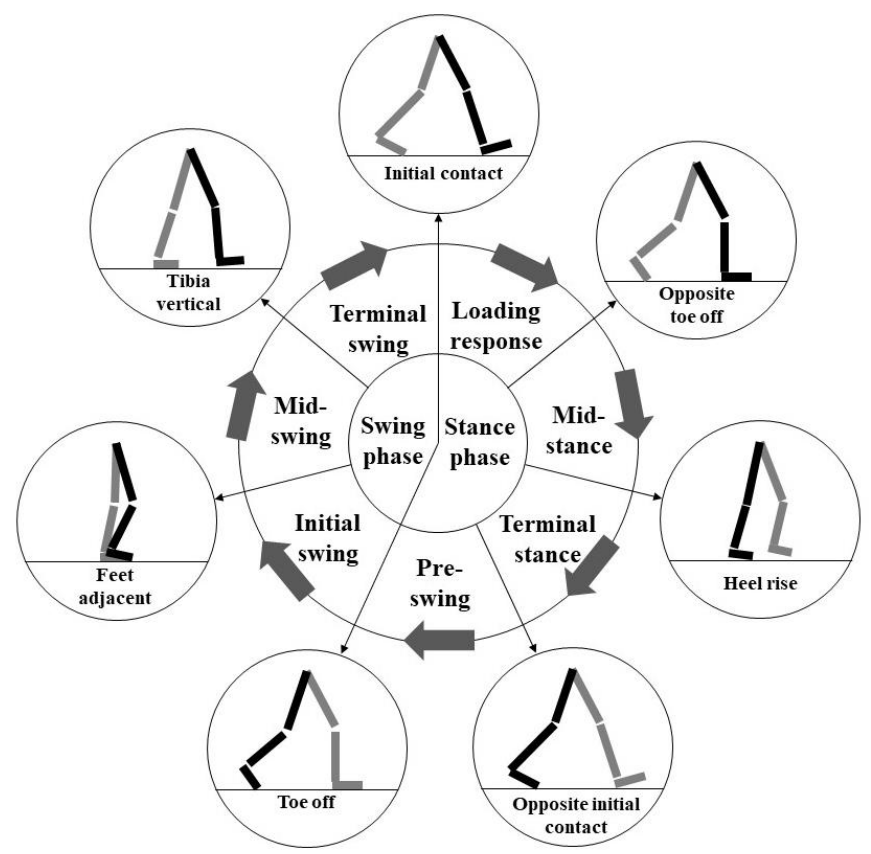

Figure 4 Two Walking phases and 7 events of the gait cycle according to (Whittle, 2006). The opposite left leg is depicted in grey and the right main leg is depicted in black

During the stance phase as it is depicted in Figure 4, the main leg is the stationary leg, and the opposite leg is the moving leg. Because of this most of the forces stemming from the body weight are transferred via the stationary leg to the ground. In his research Schuy points out that the GRF are particularly high during the beginning and end of the stance phase (Schuy, 2016). This corresponds to the initial contact and the toe off event in Figure 4. Furthermore, his analysis of the walking process with and without a 
prosthesis reveals characteristic differences in the measured GRF. Without a prosthesis the GRF are approximately equal during the initial contact and the toe off event. With a prosthesis, GRFs are approximately $30 \%$ higher in the initial contact event compared to the toe off event.

These findings were made on non-deformable surfaces, but their results can be transferred to deformable surfaces. Due to the aforementioned differences in the GRF while walking with and without a prosthesis, deformable surfaces will exhibit different behaviour. It is to be expected that increased GRF in the initial contact event will lead to a greater deformation of the walking surface.

This effect is further amplified by the fact that the contact area between the foot and the walking area in the initial contact event is limited to the small heel area of the foot. Thus, the GRF are distributed over a small area resulting in a high surface pressure. This high pressure leads to a high deformation of the deformable walking surface. Consequently, the displacement of the foot in the initial contact event is already high. Due to the higher GRF which occur in this event while walking with a prosthesis, the already high foot displacement is further increased. Therefore, the experience of walking with a prosthesis on deformable surfaces is negatively impacted. In the next subchapter a design solution for prosthetic feet is presented. It addresses the mentioned problems in order to improve the walking experience on deformable surfaces.

\subsection{Development of the foot sleeve}

The analysis of the function structure in subsection 3.2 leads to the conclusion that the foot of a prosthesis may benefit from optimizations achievable via additive methods. The following analysis of the gait cycle in subsection 3.3 then establishes relevant information required for the optimization. This information is now used to optimize the prosthetic foot design.

The developed product should appeal to a wide range of users. To build on existing and established products, the prosthetic foot is not redesigned. The chosen solution is a foot sleeve which provides an adapted interface to the environment. Due to the fact that it's designed around a standardized prosthetic foot it addresses a large user group.

As established during the analysis of the gait cycle, the walking experience with prosthetic feet on deformable surfaces - such as sand - is negatively impacted. This is due to the high displacement of the foot during the initial contact event. This deformation can be lessened by reducing the pressure between the geometry of the foot and the walking surface during the initial contact event. Reducing the pressure can either be achieved by lessening the involved forces during the event or by increasing the event relevant surface area. The presented solution makes use of both parameters How these two parameters - the reduction of relevant forces and the increase in relevant surface area - are translated into the foot sleeve design is described in the following. The result is a foot sleeve which integrates all aspects into one design which is depicted in Figure 5.

To reduce the forces during the initial contact event, the designed foot sleeve makes use of a dampening element in the heel area. This dampening element is realized by means of an elastic material. The resulting dampening characteristic is amplified by an internal mesostructure. The dampening element reduces the involved forces by the frictional characteristics of its deformation. The mesostructure is depicted in Figure 5 and Figure 6. The elements of the mesostructure can have varying thickness throughout the heel area. This degree of freedom can be used in two ways. One, to achieve more or less dampening and two, to change the characteristic dampening curve. This is done by implementing thicknesses gradients. Thus, the design allows for a non- linear dampening. With this it is possible to mainly dampen the first impulse of the impact, but still offer the necessary strength during the remaining part of the movement.

In addition to lessening the pressure by reducing involved forces, the foot sleeve also lessens the pressure by increasing the surface area. To maintain a sleek design and low mass despite the increased surface area, undercuts are used.

As stated during the identification of optimization areas, the asymmetric displacement of single a prosthetic foot in combination with a human foot, further negatively effects the walking process. If one assumes that users wear the foot sleeve to enhance their walking experience on sand, it can also be assumed that he the human foot is bare and not covered by a shoe. Thus, one needs to ensure that the vertical offset introduced by the foot sleeve is minimal. This is done by designing a particularly thin sole. As a result, both legs are of roughly the same total length. If the foot sleeve is not used on sand or paired with a shoe whose sole is thicker than $5 \mathrm{~mm}$ the sole thickness can be adjusted. As a result the vertical offset can be completely eliminated. 

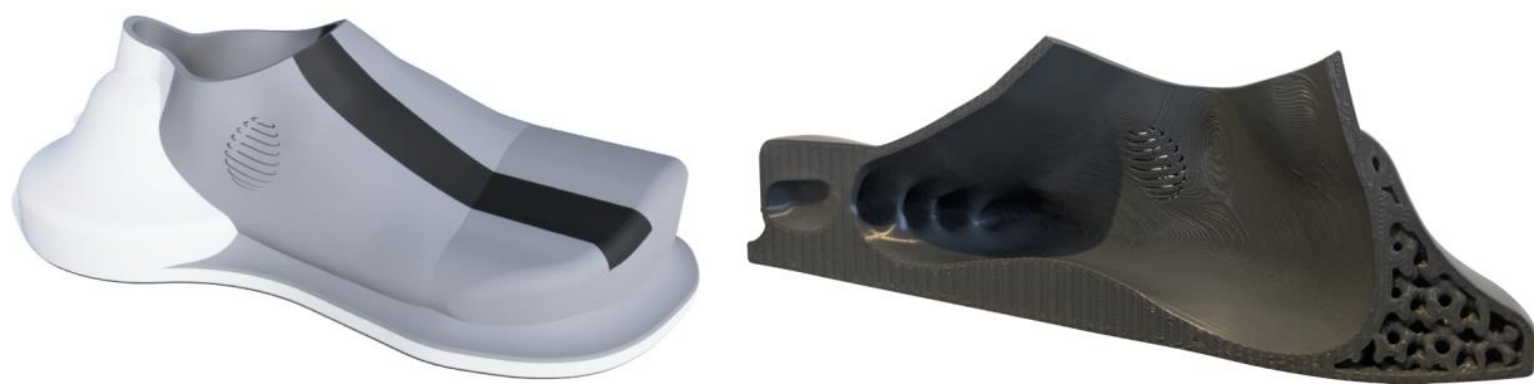

Figure 5 Digital model of the foot sleeve (left), 3D printed cross section model of the foot sleeve (right)

\subsection{Results}

To summarize the results, the foot sleeve is compared to other solutions. Figure 6 shows these three application variants. In each variant the heel and forefoot areas are signified by black bars. The prosthetic foot is used as a reference to divide these areas.

On deformable surfaces such as sand, the bare prosthetic foot will sink in due to its small heal surface area. Currently, common shoes are used to counteract this. The examined example shoe increases the overall surface area by $173 \%$ and the heel surface area by $167 \%$. However, the shoe has a notable disadvantage. It leads to a vertical offset of about $20 \mathrm{~mm}$ which in return results in an uneven gait. The designed foot sleeve builds upon the advantages of the common shoe and minimizes its disadvantages. The sleeves overall sole surface area is $254 \%$ (401\% in the heel area) larger than that of the bare prosthetic foot. It also reduces the maximum vertical offset to $5 \mathrm{~mm}$. Further numeric comparisons can be taken from Table 1 .
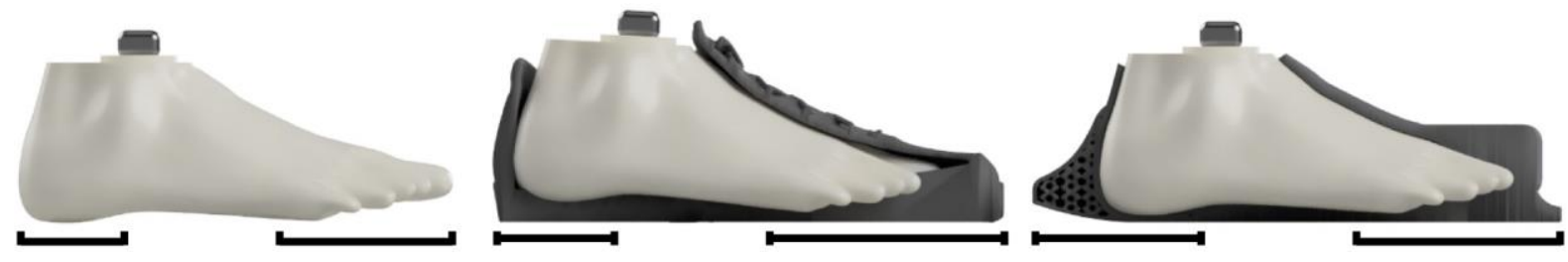

Figure 6. Typical prosthesis foot (left), prosthesis foot in a common shoe (middle), prosthesis foot in the optimized foot sleeve (right). Heel and forefoot area signified by black bars.

Additionally, the introduced mesostructure in the heel area of the sleeve dampens occurring forces during the initial contact of the foot with the walking surface. This further decreases the sleeve sinkage on deformable surfaces. Furthermore, the variable thickness of the mesostructure elements allow for a customizable dampening and spring characteristic. This can be used the individualize the foot sleeve to different environments and users. This is not possible with common shoes. Both the mesostructure and the used undercuts, which allow for the elegant design, require the use of additive manufacturing. The 3D model of the foot sleeve optimized for the potentials of additive manufacturing is published on the platform (Steffan et al., 2020b). There it and a cross section model, which highlights the mesostructure are available. The available design is based on a male foot which is $27 \mathrm{~cm}$ in length. This roughly corresponds to a shoe size of EU 42- 43.

Table 1. Comparison of the key performance indicators of a foot prothesis, a foot prosthesis in a common shoe and a foot prosthesis in the optimized foot sleeve

\begin{tabular}{lccc}
\hline & $\begin{array}{c}\text { Prothesis } \\
\text { (left) }\end{array}$ & $\begin{array}{c}\text { Prothesis in common shoe } \\
\text { (middle) }\end{array}$ & $\begin{array}{c}\text { Prothesis in } \\
\text { optimized foot } \\
\text { sleeve (right) }\end{array}$ \\
\hline $\begin{array}{l}\text { Heel Surface } \\
\text { in } \mathrm{mm}^{2}\end{array}$ & $4251(100 \%)$ & $7083(167 \%)$ & $17035(401 \%)$ \\
$\begin{array}{l}\text { Forefoot Surface } \\
\text { in } \mathrm{mm}^{2}\end{array}$ & & & \\
& $8157(100 \%)$ & $16916(207 \%)$ & $17000(208 \%)$
\end{tabular}




\begin{tabular}{lccc}
\hline & $\begin{array}{c}\text { Prothesis } \\
\text { (left) }\end{array}$ & $\begin{array}{c}\text { Prothesis in common shoe } \\
\text { (middle) }\end{array}$ & $\begin{array}{c}\text { Prothesis in } \\
\text { optimized foot } \\
\text { sleeve (right) }\end{array}$ \\
\hline Overall Surface in $\mathrm{mm}^{2}$ & $19550(100 \%)$ & $33750(173 \%)$ & $49638(254 \%)$ \\
$\begin{array}{l}\text { Vertical offset } \\
\text { in mm }\end{array}$ & $0 \mathrm{~mm}$ & $20 \mathrm{~mm}$ & $\leq 5 \mathrm{~mm}$ \\
$\begin{array}{l}\text { Adjustment of damping and } \\
\text { spring characteristic }\end{array}$ & Fixed & Fixed & $\begin{array}{c}\text { User } \\
\text { individualized }\end{array}$ \\
\hline
\end{tabular}

\section{CONCLUSION}

This contribution describes the application of an extended approach for optimization through the potentials of additive manufacturing. The extended approach is applied to an existing mechanical transtibial prosthesis. The functions of the transtibial prosthesis were analysed and a function structure was derived. Subsequently, functional characteristics were used to identify optimization areas of the transtibial prothesis for additive manufacturing. Based on this analysis, the surface of the prosthetic foot which interacts with the walking surface was deemed interesting for optimization. This is the case because current prosthetic feet are not suited for walking on deformable surfaces such as sand. To solve this problem a solution was developed which specifically makes use of additive manufacturing. To obtain relevant development information the gait cycle was evaluated using an existing model. While doing so special attention was payed to the forces which occur while waking with a prosthesis. The developed solution reduces the displacement of the foot on deformable surfaces during all walking phases by increasing the contact area. Additionally, a mesostructure was added to the heal area of the design. It dampens specifically high forces during the initial contact of the heal with the walking surface. This reduction further lessens the amount by which the prosthesis foot is displaced whilst walking on deformable surfaces. Further research on this topic can be divided into two areas. The first area refers to the application of the extended approach. During the application of the approach, optimization areas were found in a targeted manner. The currently established functional characteristics only partly cover the known potentials of additive manufacturing. To address this further, functional characteristics have to be determined. These need to be based on alternative potentials of AM. Furthermore, the development process employed in this contribution heavily relied on experiences with various additive manufacturing processes. In order to improve the usability of the extended approach, users with insufficient AM experience need to be supported. This can be done in various ways. One way would be to employ mood boards with additively manufactured products and components to enhance the solution generation process. Another way would be the use of checklists. These could contain design guidelines for additive manufacturing and general potentials of different AM processes.

The second research area covers the developed foot sleeve itself. Its performance has to be tested on different deformable surfaces such as sand. Additionally, it has to be compared to the standard prosthetic foot design. Another aspect which requires further research is the experimental determination of the of the dampening and spring characteristics in the heel area of the foot sleeve. Based on this, the mesostructure can be adjusted to meet induvial needs. Lastly an assessment of the foot sleeves handling characteristics while putting it on and taking it off can be used to further improve its user focused design.

\section{REFERENCES}

Ce:koon Prothesis Covers (2020), Homepage, Available at: https://www.cekoon.com/ (3. October 2020). Feldhusen, J. and Grote, K.-H. (2013), "Lösungsfindung: Einleitung", In: Feldhusen, J. and Grote, K.-H. (Eds.), Konstruktionslehre Methoden und Anwendung erfolgreicher Produktentwicklung, Springer-Verlag, Berlin, pp. 283-291. http://doi.org/10.1007/978-3-642-29569-0.

Feldhusen, J., Grote, K.-H., Göpfert, J. and Tretow, G. (2013), "Technische Systeme", In: Feldhusen, J. and Grote, K.-H. (Eds.), Konstruktionslehre Methoden und Anwendung erfolgreicher Produktentwicklung, Springer-Verlag, Berlin, pp. 237-278. http://doi.org/10.1007/978-3-642-29569-0.

Haberfellner, R., Weck, O. de, Fricke, E. and Vössner, S. (2019), Systems Engineering, Springer International Publishing, Cham. http://doi.org/10.1007/978-3-030-13431-0. 
Kamrad, I., Söderberg, B., Örneholm, H. and Hagberg, K. (2020), "SwedeAmp-the Swedish Amputation and Prosthetics Registry: 8-year data on 5762 patients with lower limb amputation show sex differences in amputation level and in patient-reported outcome", Acta orthopaedica, Vol. 91 No. 4, pp. 464-470. http://doi.org/10.1080/17453674.2020.1756101.

Kate, J. ten, Smit, G. and Breedveld, P. (2017), "3D-printed upper limb prostheses: a review", Disability and rehabilitation. Assistive technology, Vol. 12 No. 3, pp. 300-314. http://doi.org/10.1080/17483107.2016.1253117.

Kozak, L.J. and Owings, M.F. (1998), "Ambulatory and inpatient procedures in the United States, 1995", Vital Health Stat, Vol. 13 No. 139, pp. 1-119.

Kröger, K., Berg, C., Santosa, F., Malyar, N. and Reinecke, H. (2017), "Lower Limb Amputation in Germany", Deutsches Arzteblatt international, Vol. 114 No. 7, pp. 130-136. http://doi.org/10.3238/arztebl.2017.0130.

Maier, U., Ottobock SE \& Co KGaA (2018), DE102018133486A1, Verfahren zum Herstellen eines Prothesenschaftes und Prothesenschaft, Available at: https://worldwide.espacenet.com/patent/search/family/070969710/publication/DE102018133486A1?q=DE1 02018133486A1 (22. March 2021)

Össur (2020), Nach der Beinamputation zurück ins Leben, Available at: https://res.cloudinary.com/ossur/image/upload/v1580891868/documents/Documents_DE/2020_\%C3\%96ss ur._Nach_der_Beinamputation-Zur\%C3\%BCck_ins_Leben.pdf (15. August 2020).

Ottobock (2020), Homepage - Prothesen - Produkte, Available at: https://www.ottobock.de/prothesen/produktevon-a-bis-z/ (15. August 2020).

Pahl, G., Beitz, W., Feldhusen, J. and Grote, K.-H. (2007), Engineering Design, Springer London, London. http://doi.org/10.1007/978-1-84628-319-2.

Petrovic, V., Vicente Haro Gonzalez, J., Jordá Ferrando, O., Delgado Gordillo, J., Ramón Blasco Puchades, J. and Portolés Griñan, L. (2011), "Additive layered manufacturing: sectors of industrial application shown through case studies", International Journal of Production Research, Vol. 49 No. 4, pp. 1061-1079. http://doi.org/10.1080/00207540903479786.

Piazza, C., Grioli, G., Catalano, M.G. and Bicchi, A. (2019), "A Century of Robotic Hands", Annual Review of Control, Robotics, and Autonomous Systems, Vol. 2 No. 1, pp. 1-32. http://doi.org/10.1146/annurevcontrol-060117-105003.

Ponn, J. and Lindemann, U. (2008), Konzeptentwicklung und Gestaltung technischer Produkte: Optimierte Produkte - systematisch von Anforderungen zu Konzepten, Springer-Verlag, Berlin Heidelberg. http://doi.org/10.1007/978-3-540-68563-0.

Schuy, J. (2016), Variable Torsionssteifigkeit in Unterschenkelprothesen zur aktiven Unterstützung in dynamischen Gangsituationen, Dissertation, Technische Universität Darmstadt. https://tuprints.ulb.tudarmstadt.de/5733/

Sonova (2020), 3D printing technology for improved hearing, Available at: https://www.sonova.com/en/story/ innovation/3d-printing-technology-improved-hearing (7. December 2020).

Steffan, K.-E., Fett, M. and Kirchner, E. (2020a), "Extended Approach to Optimize Modular Products Through the Potentials of Additive Manufacturing", DESIGN Conference, Croatia, 26. - 29. October 2020, Cambridge University Press, Cambridge, pp. 1115-1124. http://doi.org/10.1017/dsd.2020.172.

Steffan, K.-E., Fett, M. and Kurth, D. (2020b), Identification of optimization areas of a transtibial prosthesis through the potentials of additive manufacturing processes foot prosthesis sleeve, Available at: https://tudatalib.ulb.tu-darmstadt.de/handle/tudatalib/2543 (10. December 2020). http://doi.org/10.25534/tudatalib-390.

United Nations (2019), World Population Prospects, Available at: https://population.un.org/wpp/Publications/ Files/WPP2019_Volume-I_Comprehensive-Tables.pdf (2. December 2020).

Verein deutscher Ingenieure (2019), VDI 2221 Part 1, Design of technical products and systems: Model of product design, Beuth Verlag GmbH.

Whittle, M.W. (2006), An Introduduction to Gait Analysis, Butterworth-Heinemann Ltd, London.

World Health Organization (2011), World Report on Disability, Available at: https://apps.who.int/iris/bitstream/handle/10665/70670/WHO_NMH_VIP_11.01_eng.pdf;jsessionid=D5A8 F43168DF7612DA8D193DB1F38524? sequence=1 (6. November 2020). 